\title{
Behavioural Problems and Parental Over-protectiveness in Children with Asthma
}

\section{Sawant $\mathbf{N}^{1}$, Bhargava $\mathrm{J}^{2}$, Deshmukh $\mathrm{CT}^{3}$}

${ }^{1}$ Dr. Neena S Sawant, MBBS, MD. Professor (Additional), Department of Psychiatry, ${ }^{2} \mathrm{Ms}$. Juhi Bhargava, Illrd Year MBBS Student, ${ }^{3} \mathrm{Dr}$. Chandrahas T Deshmukh, Professor and Head of Unit, Department of Paediatrics. All from the Seth GSMC and KEM Hospital, Mumbai, India.

\section{Address for correspondence:}

Prof. Neena S Sawant

Professor (Addl), Department of Psychiatry, Seth GSMC and KEM Hospital,

Parel, Mumbai- 400012

Tel (O): +9122-2410-7492

E-mail: drneenas@yahoo.com

Acknowledgements: None

Funding: Nil

Conflict of Interest: None

Permission from IRB: Yes

Ethical dilemmas faced during study: There were no ethical dilemmas. Parents of children detected to be having behavioural problems were informed and offered the services of the child guidance clinic of the Dept of Psychiatry for further evaluation and management.

\section{How to cite}

Sawant N, Bhargava J, Deshmukh CT. Behavioural Problems and Parental Overprotectiveness in Children with Asthma. J Nepal Paediatr Soc 2016;36(3):232-237.

doi: http://dx.doi.org/10.3126/jnps.v36i3.15378

This work is licensed under a Creative Commons Attribution 3.0 License.

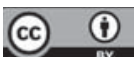

\begin{abstract}
Introduction: Asthma in children often leads to behavioural problems due to the chronic nature of the disease. Parents also tend to be overprotective and many may not even consult a doctor for the same. The objectives were to study the various behavioural problems seen in children having asthma as compared to those with minor ailments, parental awareness about the same and their parenting styles. Material and Methods: 75 parents of children of bronchial asthma and 75 parents of children having short term minor ailments formed the asthma and control groups respectively. The Behaviour Problem Index was used to assess the behavioural problems in children as documented by parents and parental overprotectivenesswas assessed using the Vulnerable Child/ Overprotecting Parent Scale. Results:The demographic variables were comparable in both the groups. Behavioural problems on all domains and parental over protectiveness in the asthma group were found to be statistically significant as compared to control group. However there was no significant correlation between the parental over-protectivenessand the behavioural problems in both the groups. Conclusions: Early referral to the psychiatrist with parental counselling will result in better outcomes for the child.
\end{abstract}

Key words: Behavioural problems, over protectiveness, children of asthma, chronic illness, parental attitude

\section{Introduction}

A sin sthma is a commonly occurring illness seen in children living in metropolitan cities and is a growing concern among health professionals due to the increase in the cases caused by pollution and socioeconomic problems seen in the ever growing cities. Children with asthma not only have a chronic disease that impacts their lives, but they are also more likely to have behavioural and emotional problems, compared to children without asthma ${ }^{1,2,3,4,5}$.

Epidemiological studies have shown that about $15 \%$ of children and adolescents, on average, have a chronic physical health condition $^{6}$. These conditions are risk factors for behavior problems. Much research in asthma in children has been directed to the child's personality,parent-child interaction, parental attitudes to the child and the relation of emotional disturbance to asthma. Asthmatic children 
have been reported to show a variety of externalizing and internalizing problems. Externalizing problems include delinquent and aggressive behaviors, and internalizing problems include somatic complaints, anxiety, depression, lack of self-confidence, dependence and social withdrawal ${ }^{7,8}$. The reason for increased behavioural problems in children with asthma is still unknown as is the cause of asthma itself.

Pinquart and Shen ${ }^{9}$ have emphasized on the need for analyzing the prevalence of behavior problems of children with chronic physical illness and identifying related risk factors so that it can help to understand psychosocial consequences of chronic physical diseases. This would also help clinicians in early identification of children at risk and provide appropriate integrated treatment. Since many chronic diseases cannot be cured, the goal is to reduce the consequences of the diseases on the lives of children and adolescents. Parental stress is a potential determinant of behavioral problems in the children as indicated by studies that observed a correlation between a negative family emotional climate, child internalizing symptoms and asthma severity ${ }^{10,11,12}$. On the other hand, parental over protectiveness can also be harmful for the child's overall development ${ }^{13}$.

Children with asthma are also frequently absent from school because of acute attacks or exacerbations of asthma, inter-current infections, poor physique and the need to attend hospitals for treatment and therapy sessions ${ }^{14,15}$. Despite an increasing prevalence of chronic childhood conditions and heightened concerns for the quality of life of the chronically ill, there is a dearth in Indian literature on studies on behaviour problems among children with major illness like asthma and / or minor illnesses. Awareness about emotional and behavioural illnesses and the need to take an early referral is also lacking among parents. Much of the literature available is from developed countries. Hence we undertook this research to compare the differences in the behavioural and emotional problems, school absenteeism due to the illness, parental awareness regarding behavioural problems and parental overprotectiveness in children of asthma and those having minor ailments.

\section{Material and Methods}

The study was conducted in parents of children of asthma who attended the specialised asthma OPD held once a week in the paediatric OPD of a tertiary care general municipal hospital. It was an observational cross sectional study initiated after approval from the
Institutional Review Board in accordance with the ethical standards as per the Helsinki Declaration.

All children of bronchial asthma diagnosed by the consultant paediatrician were included in study. There are approximately $700-750$ cases of bronchial asthma per year following up regularly in the specialised asthma OPD of the paediatric department. 104 parents of children of asthma who were aged 4-12 years and diagnosed as having asthma on regular treatment since at least 1 year were screened. As per universal sampling $70 \%$ of this sample $(n=75)$ who fulfilled the inclusion and exclusion criteria and were willing to participate were enrolled in the study over a period of two months after valid informed consent. They formed the asthma group. The control group for the study was matched for the socio-demographic profile and included 75 parents of children following up in the paediatric OPD for some minor ailments like cough, fever and gastrointestinal disorders etc which were not chronic ailments. In either groups children having any other major medical co-morbidity or already diagnosed with a psychiatric problem and/or on any psychiatric medication were excluded from the study.

A semi structured preformat was designed to collect information on the various demographic variables, phenomenological factors such as duration of bronchial asthma in the child, history of school absenteeism due to the illness, open ended questions on parental awareness about the child's behaviour and scales pertaining to the aims of the study.

\section{Tools}

1. Behaviour Problems Index (BPI) ${ }^{16}$ : The $\mathrm{BPI}$ is a 28-item,3 point likert rated scale for parent report of child behaviour aged 4-17years exhibited in the previous three months. It taps some of the more common behaviour syndromes in children on 6 domains of antisocial behaviour, anxiousness/ depression, headstrongness, hyperactivity, immaturity/dependency and peer conflict/social withdrawal. BPI also measures a child's tendency to internalize or externalize behaviours with the help of total and domain scores.

2. Vulnerable Child/Overprotecting Parent Scale (VCOPS) ${ }^{17}$ : The VCOPS is a 28 item, 6 point likert rated standardised instrument used for measuring the overprotecting vs. optimal developmental stimulation tendencies of parents of disabled, atrisk, or vulnerable children. It gives a total score. Higher scores indicate over protectiveness. 
The department of psychiatry has six psychiatrists, two psychologists and two psychiatric social workers who do the translation of scales with back translation for the various studies. If the study involves liaison, then a faculty of the respective discipline is also involved in the translation. For this study both the scales were translated in Hindi and Marathi by a three member team consisting of psychiatrist, psychologist and paediatrician. The translated scales were then back translated by another psychiatrist. All the translated scales were submitted to the institutional ethics committee for approval with the certificate of back translation given by the concerned faculty.

Demographic variables were studied with the help of frequency distribution, $t$-test and chi square wherever applicable. Group differences in behavioural and emotional problems and parental attitudes were studied using the student's $t$-test. The parental awareness about the presence of behavioural problems were analysed using the frequency distribution. The association between parental over-protectiveness and behaviour problems was correlated with the help of Pearson's correlation coefficient.

Permission from the Institutional Review Board was taken to do this study.

\section{Results}

Demographic and IIIness Variables: The mean age of children in the asthma group was $8.78 \pm 1.82$ years and in the control group it was $8.94 \pm 1.52$ years. In both the groups there was a male preponderance with the male: female ratio being $2: 1$. In the asthma group nearly $50 \%$ were staying in nuclear and joint/extended families each whereas in the control group only $25 \%$ were staying in joint and extended families. In both the groups majority $(75 \%)$ of the children were Hindus, all belonged to lower socioeconomic strata and the father was the major earning member. There were no significant differences seen in age, gender, family type and religion and hence both the groups were comparable.

The mean duration of asthma was $3.2 \pm 2.9$ years whereas in the control group the illness ranged from 1-5 days. When both the groups were studied for prevalence of school absenteeism in the last six months due to illness then a significant difference was seen with nearly $72 \%$ of children with asthma having school absenteeism as compared to only $13 \%$ of the children having minor illnesses. The number of days missed were in the range of 2-7 days in the asthma group as compared to 1-3 days in the control group.Table1
Behavioural problems as per BPI: When both the groups were assessed for presence of behavioural problems in the various domains of the BPI then a highly significant difference was seen with the children of asthma having severe behavioural problems than the control group on all the domains of antisocial $(t=6.18, p<$ 0.001 ), anxious/depressed ( $t=10.6, p<0.001)$, dependant ( $t=10.07, p<0.001)$, headstrongness $(t=8.40, p<0.001)$, hyperactivity $(t=6.59, p<0.001) \&$ peer pressure $(t=7.29$, $p<0.001)$. The mean total BPI scores were $14.45 \pm 3.9$ in the asthma group as compared to $5.28 \pm 3.5$ in the control group which was also very highly statistically significant ( $t=14.9, p<0.001)$.

An assessment for the measure of externalizing or aggressive behaviour and internalizing, withdrawn or sad behaviour in both the groups also revealed a statistical significant difference with the children of asthma having more externalising $(t=12.2, p<0.001)$ and internalising ( $t=11.9, p<0.001)$ behaviours than the control group children.

The BPI gives the parental perception of the emotional and behavioural issues which when analysed on the various domain behaviours revealed the children with asthma to have more headstrongness (68\%), anxious depressed behaviours (60\%), dependent behaviours $(60 \%)$, hyperactivity $(49 \%)$, peer problems (43\%) and antisocial issues (24\%). On the other hand in the control group children, the predominant domain behaviours were headstrongness $(17 \%)$, hyperactivity $(12 \%)$, dependent behaviours $(9 \%)$, anxious depressed behaviours $(7 \%)$, peer problems $(5 \%)$ and antisocial issues (3\%).In both the groups headstrongnesswas more predominant whereas antisocial behaviours were the least prevalent.Table2

Though the parents expressed so many behavioural issues in their children, surprisingly only $7(9 \%)$ parents of asthma group and $3(4 \%)$ in control group felt that the child should be referred to a counselor or a psychiatrist. None of them had reported the symptoms to the treating physician.

Parental Over-protectiveness: When both the groups were assessed for differences in overprotectiveness then a significant difference was seen with the parents of asthma group being more overprotective than the control group parents $(t=2.563, p<0.01)$. Table3

Also when each group was studied for the association of parental over-protectiveness and its impact on behavioural problems in the children then in both the groups no significant correlation was seen. Table 4 
Table 1: Demographic and IIIness Variables

\begin{tabular}{|c|c|c|c|c|}
\hline \multirow[t]{2}{*}{ Variable } & $\begin{array}{l}\text { Asthma group } \\
\qquad(n=75)\end{array}$ & $\begin{array}{l}\text { Control group } \\
\qquad(n=75)\end{array}$ & \multirow{2}{*}{$\begin{array}{c}\text { t-test, } \\
\text { Chi square with Yates correction } \\
\text { (df) }\end{array}$} & \multirow[t]{2}{*}{$p$-value } \\
\hline & Mean \pm SD & Mean \pm SD & & \\
\hline Age in years & $8.78 \pm 1.82$ & $8.94 \pm 1.52$ & 0.5736 & 0.5671 \\
\hline \multicolumn{5}{|l|}{ Gender } \\
\hline Male & $48(64 \%)$ & $46(61 \%)$ & \multirow[b]{2}{*}{$6.02(1)$} & \\
\hline Female & $27(36 \%)$ & $29(39 \%)$ & & 0.8659 \\
\hline \multicolumn{5}{|l|}{ Family Type } \\
\hline Nuclear & $39(52 \%)$ & $53(71 \%)$ & \multirow{3}{*}{$7.03(2)$} & \multirow{3}{*}{0.629} \\
\hline Joint & $22(29 \%)$ & $17(23 \%)$ & & \\
\hline Extended & $14(19 \%)$ & $5(6 \%)$ & & \\
\hline \multicolumn{5}{|l|}{ Religion } \\
\hline Hindu & $52(69 \%)$ & $55(73 \%)$ & \multirow[b]{2}{*}{$0.1309(1)$} & \multirow[b]{2}{*}{0.7180} \\
\hline Muslim \& Others & $23(31 \%)$ & $20(27 \%)$ & & \\
\hline \multicolumn{5}{|l|}{ Earning member } \\
\hline Father & $75(100 \%)$ & $75(100 \%)$ & \multirow{3}{*}{$0.0271(2)$} & \multirow{3}{*}{0.986} \\
\hline Mother & $7(9 \%)$ & $7(9 \%)$ & & \\
\hline Other & $16(21 \%)$ & $15(20 \%)$ & & \\
\hline Duration of Asthma in years & $3.202 \pm 2.96$ & & & \\
\hline \multicolumn{5}{|l|}{ School Absenteeism } \\
\hline Present & $54(72 \%)$ & $10(13 \%)$ & & \\
\hline Absent & $21(28 \%)$ & $65(87 \%)$ & $50.39(1)$ & $0.0001^{*}$ \\
\hline
\end{tabular}

*highly significant

Table 2: Behavioral disturbances as per BPI

\begin{tabular}{lcccccc}
\hline \multirow{2}{*}{ BPI domains } & \multicolumn{2}{c}{ Asthma group $(\mathbf{n = 7 5 )}$} & \multicolumn{2}{c}{ Control group $(\mathbf{n}=75)$} & & \\
\cline { 2 - 7 } & $\begin{array}{c}\text { No. of } \\
\text { children(\%) }\end{array}$ & Mean \pm SD & $\begin{array}{c}\text { No. of } \\
\text { children(\%) }\end{array}$ & Mean \pm SD & $t$-test & $p$ - value \\
\hline Antisocial & $18(24 \%)$ & $2.33 \pm 1.51$ & $2(3 \%)$ & $.9600 \pm 1.17$ & 6.186 & $0.0001^{*}$ \\
\hline Anxious/Depressed & $45(60 \%)$ & $2.72 \pm 1.23$ & $5(7 \%)$ & $.720 \pm 1.06$ & 10.63 & $0.0001^{*}$ \\
\hline Dependant & $45(60 \%)$ & $2.693 \pm 1.19$ & $7(9 \%)$ & $.8000 \pm 1.10$ & 10.07 & $0.0001^{*}$ \\
\hline Headstrongness & $51(68 \%)$ & $2.907 \pm 1.24$ & $13(17 \%)$ & $1.240 \pm 1.18$ & 8.409 & $0.0001^{*}$ \\
\hline Hyperactivity & $37(49 \%)$ & $2.507 \pm 1.32$ & $9(12 \%)$ & $1.187 \pm 1.11$ & 6.598 & $0.0001^{*}$ \\
\hline Peer Pressure & $32(43 \%)$ & $1.33 \pm 0.92$ & $4(5 \%)$ & $.373 \pm 0.67$ & 7.291 & $0.0001^{*}$ \\
\hline Externalizing behaviour & & $8.973 \pm 2.833$ & & $3.613 \pm 2.49$ & 12.289 & $0.0001^{*}$ \\
Internalizing behaviour & & $5.107 \pm 2.147$ & & $.533 \pm 1.464$ & 11.907 & $0.0001^{*}$ \\
Total & & $14.49 \pm 3.96$ & & $5.280 \pm 3.56$ & 14.964 & $0.0001^{*}$ \\
\hline
\end{tabular}

*highly significant

Table 3: Parental Over-protectiveness as per VCOPS

\begin{tabular}{ccccc}
\hline \multirow{3}{*}{ vCOPS } & Asthma group $(\mathbf{n}=\mathbf{7 5})$ & Control group $(\mathbf{n}=\mathbf{7 5})$ & \multirow{2}{*}{-test } & $p$-value \\
\cline { 2 - 3 } & Mean \pm SD & Mean \pm SD & 2.563 & $0.0114^{*}$ \\
\hline
\end{tabular}

* significant

Table 4: Correlation of Behavioural problems with Parental Over-protectiveness using Pearson's correlation coefficient

\begin{tabular}{ccc}
\hline BPI total score & \multicolumn{3}{c}{ VCOPS total score } \\
\cline { 2 - 3 } & $\mathbf{r}$ & $\mathbf{P}$ \\
\hline Asthma group & -0.1584 & 0.1748 \\
\hline Control group & 0.2012 & 0.0835 \\
\hline
\end{tabular}




\section{Discussion}

Demographic and IIIness Variables: Our findings of asthma being more prevalent in males coming from a lower socioeconomic background in the age group five years and above are keeping in those of previous researchers ${ }^{14,18,19,20}$. Family income is also considered a risk factor in first-aid asthma examinations ${ }^{18}$. We had found a higher prevalence of school absenteeism in our sample. Spurrier et $\mathrm{al}^{14}$ reported the same in $42 \%$ of the children with asthma, with days of being absent ranging from 1-12 days whereas Moonie et al ${ }^{15}$ found that those with asthma were absent for a mean of 9.2 days approximately 1.5 more days compared to those without asthma.

Behavioural problems as per BPI: Our overall findings indicated that children who had asthma were shown to have more behaviour problems compared to children with minor ailments keeping in with the findings of several researchers ${ }^{2,3,4,5,21}$ ranging from $21 \%{ }^{6}$ to $35 \%{ }^{21}$. In a similar study Bussing et al ${ }^{5}$ found that children with asthma and co-morbid conditions had a mean BPI score of 7.3 , compared with 5.4 for children without chronic conditions, and all subscale scores, except those for antisocial conduct and immature behaviour, were significantly elevated. Halterman et $\mathrm{al}^{3}$ found that children with asthma had a higher number of behavioural problems across several domains. They were more anxious and depressed with negative peer scores and had difficulty in task orientation as compared to other children. These findings also corroborate our findings of anxious depressed mood, peer problems and hyperactivity seen in asthma children. Bussing et $\mathrm{al}^{5}$ found viz headstrong behaviours, followed by anxious depressed behaviours, hyperactivity, antisocial behaviours, immature behaviours, and peer conflict as the most to the least common reported problem behaviours respectively by parents in all their four study groups with the exception of anxiety-depression which was elevated in children with asthma alone. In both our groups we also found an identical trend though antisocial behaviours were the least common.

There usually is a cause or effect relationship between chronic illnesses and psychosocial disturbances. Hence most of the parents of children of asthma found the emotional and behavioural consequences in their offspring's but probably accepted it as a part of the illness and did not feel it warranted reporting to the treating physician. Despite the fact that most of the asthma children had higher scores on almost all domains indicating the need for intervention, the parents had no understanding of these behaviours or the need to seek appropriate treatment.

We did not use any structured clinical interview in children to confirm the diagnoses of these emotional and behavioural problems and neither does the BPI give a psychiatric diagnoses or assess any social competency. Our findings of more externalizing behaviors' in children of asthma differ from other studies where elevated levels of internalizing behaviors' such as being withdrawn/ depressed and more severe somatic complaints in children with asthma were seen ${ }^{2,7,8}$. The probable reason for this could be due to a high prevalence of headstrongness and antisocial behaviors seen in the children of asthma as compared to those children having minor ailments. Another reason could be the high over protectiveness which parents felt towards these children which would probably allow them to pamper and give in to demands. Majority of the children with asthma were also staying in joint and extended families which often allows the child to have the demands met by another elder in the family which is commonly seen in Indian households.

Parenting styles: The parents of the asthma children were more over involved and overprotective as compared to the control group parents. A child with asthma is often seen as vulnerable and parents try to restrict their outdoor activities, are less strict with them and more sentimental in their behaviours as the child has a chronic illness. A meta-analytic review suggested that parenting stress is higher in caregivers of children with any chronic illness than in caregivers of healthy children ${ }^{22}$. Most evidence indicates that parenting stress in children with asthma is in the normal range compared to healthy controls and norm reference groups ${ }^{23,24,25}$ except for Verkleij et al ${ }^{11}$ who found lower levels of parental stress in parents of children having severe asthma.

Our study looked at parenting styles with respect to giving the child autonomy in his activities, freedom to express, improving child's self esteem etc. There are several studies that have reported parental stress as a potential determinant of behavioral problems in the children where a correlation between a negative family emotional climate and child internalizing symptoms ${ }^{12}$ were seen but in our study no correlation was found between parenting styles and behaviour problems.

\section{Conclusions}

The findings of this study emphasize the importance of planning for the mental health services needs of children with chronic conditions like asthma as behavioural and emotional problems are seen in them. 
Early referral to the psychiatrist by the paediatrician and parental counselling will definitely result in early detection and better management of the behavioural and emotional problems in these children.

Limitations of the Study: It is not representative of a community sample and future comparative longitudinal studies looking at behavioural and emotional problems in other chronic illnesses and normal children would throw more light on the extent and severity of the problem.

Recommendations: Studies using structured clinical interviews, appropriate psychometric tests, and comprehensive child care services and understanding the effect of medicines used in asthma treatment on behaviour would all help in finding the causal relationship of emotional and behavioural problems with childhood asthma.

\section{References}

1. Stevenson J. Relationship between behavior and asthma in children with atopic dermatitis. Psychosomatic Med 2003;65:971-75.

2. Alati R, O'Callaghan M, Najman J, Williams B, Lawlor D.Asthma and Internalizing Behavior Problems in Adolescence: A Longitudinal Study. Psychosomatic Med 2005;67:462-470.

3. Halterman J S, Conn KM, Forbes-Jones E, Fagnano M, Hightower AD,Szilagyi PG. Behavior problems among inner-city children with asthma: Findings from a community-based sample. Pediatrics 2006;117(2):19299.

4. Blackman J A, GurkaM J. (2007). Developmental and Behavioral Comorbidities of Asthma in Children. J Dev Behavior Pediatr 2007;28(2):92-99.

5. Bussing R, Halfon N, Benjamin B, Wells KB.Prevalence of behavior problems in US children with asthma. Arch PediatrAdol Med 1995;149(5):565-72.

6. van der Lee J, Mokkink L B, Grootenhuis M A, Heymans HS, Offringa M. Definitions and measurement of chronic health conditions in childhood: A systematic review. JAMA 2007;29: 2741-751.

7. McQuaid EL, Kopel SJ, Nassau JH. Behavioral adjustment in children with asthma: a meta-analysis. $J$ Dev Behav Pediatr 2001;22:430-39

8. Verkleij M, van de Griendt E J, Kaptein A A, van EssenZandvliet L E, Duiverman E J, Geenen R. Behavioral problems in children and adolescents with difficult to treat asthma. J Asthm 2011;48:18-24.

9. Pinquart $M$, Shen $Y$. Behavior problems in children and adolescents with chronic physical illness: A metaanalysis. J Pediatr Psychol 2011b;36:1003-16.

10. Wood B L, Lim J, Miller BD, Cheah P, Zwetsch T, Ramesh S,Simmens S. Testing the Biobehavioral Family Model in pediatric asthma: pathways of effect. Family Process 2008; 47:21-40.

11. Verkleij M, van de Griendt EJ,Colland V, van Loey N, Beelen A, Geenen R.Parenting Stress Related to Behavioral Problems and DiseaseSeverity in Children with Problematic Severe Asthma. J Clin Psychol Med Settings 2015;22:179-93.

12. Lim J, Wood B L, Miller BD. Maternal depression and parenting in relation to child internalizing symptoms and asthma disease activity. J Fam Psychol 2008;22:26-73.

13. Wakefield M, Staugas R, Ruffin R, Campbell D, Beilby J, McCaul K. Risk factors for repeat attendance at hospital emergency departments among adults and children with asthma. Aust N Z J Med 1997;27:277-84.

14. Spurrier NJ, Sawyer MG, StaugasR, Martin AJ,KennedyD, Streiner DL. Association Between Parental Perception of Children's Vulnerability to Illness and Management of Children's Asthma. Pediatr Pulmonol 2000;29:88-93.

15. Moonie SA, Sterling DA, Figgs L, Castro M. Asthma status and severity affects missed school days. J Sch Health 2006;76(1):18-24.

16. Peterson JL, Zill N. Marital disruption, parent-Child relationships. and behavior problems in children. J Marriage Fam 1986;.48:295-307.

17. Wright $L$, Mullen $T$, West $K$, Wyatt $P$. The VCOP Scale: A measure of overprotection in parents of physically vulnerable children. J Clin Psychol 1993;49:790-98.

18. Chatkin M, Menezes AMB, Albernaz E, Victoria $\mathrm{CG}$, Barros FC. Asthmatic children's risk factors for emergency room visits, Brazil. Rev Saúde Pública 2000;34:491-8.

19. Lundback B. Epidemiology of rhinitis and asthma. Clin Exp Allergy 1998;28:3-10.

20. Fleitlich BW, Goodman R. Social factors associated with child mental health problems in Brazil: cross sectional survey. BMJ 2001;323:599-600.

21. Feitosa CA,Darci N, Santos MB, Barreto do Carmo,Letícia M S, Carlos AS et al.(2011) Behavior problems and prevalence of asthma symptoms among Brazilian children. J Psychosom Res 2011;71(3):160-65.

22. Cousino MK, Hazen R A.Parenting stress among caregivers of children with chronic illness: a systematic review. J Pediatr Psychol 2013;38:809-28.

23. Caffrey-Craig B. Childhood asthma: A stressrelated illness? More myth than fact. Irish J Psychol 2005;26:149-59.

24. DeMore M, Adams C, Wilson N. Parenting stress, difficult child behavior, and use of routines in relation to adherence in pediatric asthma. Children's health care 2005;34:245-259.

25. Markson S, Fiese BH. Family rituals as a protective factor for children with asthma. J Pediatr Psychol 2000;25:471-480. 